\title{
Energy and Fire Safety Performance of Atrium Ventilation in High-rise Buildings
}

\author{
Haohan Sha ${ }^{1}$, Dahai Qi ${ }^{1}$, \\ ${ }^{1}$ Department of Civil and Building Engineering, University of Sherbrooke, Sherbrooke, Canada
}

\begin{abstract}
Ventilative cooling is an effective approach to remove indoor overheat, thus reducing cooling load and peak electricity demand. In high-rise buildings, the stack effect could contribute to more building ventilation and coolingrelated energy savings. However, it also brings much concern on the fire safety issues, which, therefore, blocks the ventilative cooling application in high-rise buildings due to the limited study on the interaction effects between fire safety and energy efficiency of high-rise ventilation. To fill in this research gap, this paper aims to investigate the impacts of fire safety design, i.e. adding segmentation in the high-rise atrium, on the high-rise ventilative cooling performance. Both fire smoke simulations and building energy simulations were conducted to investigate the impacts of segmentation slab on the performance of fire protection as well as the ventilative cooling. It was found that the segmentation could effectively protect the upper space which is far from the fire source, but it reduces the energy savings of ventilative cooling due to the higher flow resistance. Therefore, it is quite necessary to evaluate both of fire protection performance and energy efficiency for high-rise ventilation design.
\end{abstract}

\section{Introduction}

Building ventilation has proved to be an effective solution for cooling indoor spaces and reducing building cooling load (Cheng, Qi, Katal, Wang, and Stathopoulos, 2018), i.e. ventilative cooling (Venticool, 2016). Driven by stack effect, outdoor air can pass through horizontal floors, remove indoor heat, and exit through vertical spaces, such as atria and stairwells (Aflaki, Mahyuddin, Al-Cheikh Mahmoud, and Baharum, 2015). Stack effect refers to buoyancy-driven airflows due to a difference in indoor and outdoor air densities, which often occurs in large vertical spaces. Building ventilation could reduce cooling-related energy consumption from 56\% (Malkawi, Yan, Chen, and Tong, 2016) to 86\% (Hu and Karava, 2014). Due to cold climates, high-rise ventilative cooling (HVC) is available for a long time throughout the year in Canada and Northern Europe, not only during shoulder seasons, but also in summer periods (Artmann, Manz, and Heiselberg, 2007). Cold climates are featured by large diurnal temperature variations and relatively low nighttime temperatures even in the summer. A high-rise building structure can be cooled during the night and provide a huge heat sink during the daytime significantly for reducing cooling loads and thus peak electricity demands.

However, one of the major concerns to adopt HVC is the fire safety concern associated with the stack effect in large vertical spaces. During regular operations, many existing features and functions of these large spaces can contribute to the stack effect and ventilative cooling for a potential maximum level of energy savings. However, during fire outbreaks, they could become major spreading routes for fire-generated smoke laden with toxic gases to spread far away from the fire origins deep throughout the buildings, endangering people's lives, causing property damage and generating obstacles for firefighters, e.g. the Joelma Building, Brazil (189 deaths, 1974); the Dupont Plaza Hotel Fire, US (97 deaths, 1986); and the most recent Grenfell Tower fire in London, UK (80 deaths, 2017) (Wikipedia, 2018). The problem can be further complicated by interactions with dynamic weather conditions including variable winds, temperatures and building system operations. Therefore, it is important to understand the interplays of all the contributing parameters and different situations. As one of the key spaces in high-rise buildings, atrium spins several floors or even as high as the whole high-rise. It provides a feeling of space and light and is an ideal space for natural ventilation driven by stack effect (Moosavi, Mahyuddin, Ab Ghafar, and Azzam Ismail, 2014). However, it is also the most important place for fire protection design due to its tall and large space. Therefore, it is important to investigate the fire safety and energy performance of the atrium in high-rise buildings.

To explore the impact of fire protection design on the energy efficiency of high-rise ventilative cooling, this paper presents the study on the ventilation in the atrium. Fire protection method is adding a segmentation floor slab in the atrium to reduce stack effect. Fire smoke model and building energy model were developed for numerical simulation. Through the energy and fire smoke simulations in a high-rise atrium, the energy and fire safety performance are discussed.

\section{Methods}

\section{Building information}

This study focuses on an institutional high-rise building in Montreal, Canada. This building has 16 floors with a $30.6 \mathrm{~m}$ high atrium spanning six floors as is shown in Figure 1. The atrium includes west and north glazing façades. The floor geometry of the atrium is a rectangle 
with $11.9 \mathrm{~m}$ width and $30.0 \mathrm{~m}$ length. Cooling and heating are supplied by the HVAC system and there is no natural ventilation $(\mathrm{NV})$ in the real operation.

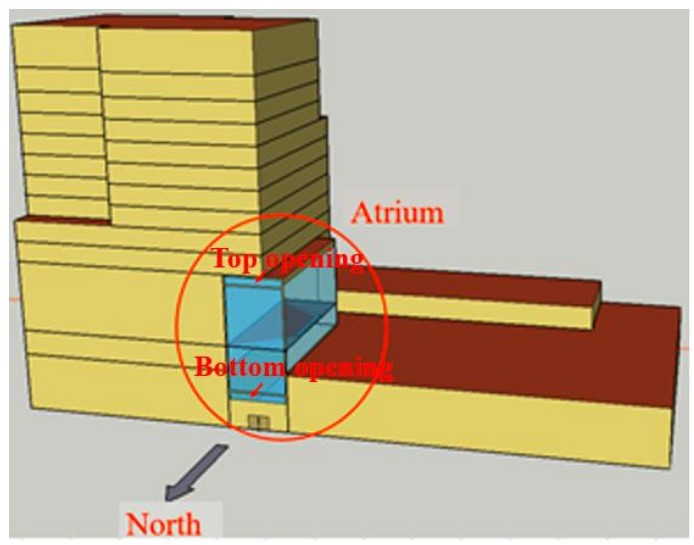

Figure 1: The building model.

\section{Fire smoke simulation}

In order to exhaust the smoke from the inside building, a smoke shaft is designed as shown in Figure 2. Once a fire occurs, the smoke fan, which is installed on the top of the shaft, will work and remove the smoke. Considering high vertical space leads to high stack effect, which is a challenge for fire protection design, segmentation is often used in the large vertical spaces to lessen stack effect (Cheng, Qi, Wang, and Athienitis, n.d.; Yuan, Vallianos, Athienitis, and Rao, 2018). Here, the floor slab is applied at the bottom of the fourth floor (height: $16.5 \mathrm{~m}$ ) to separate the atrium into two parts as Figure 2 shows. Two scenarios were designed, no segmentation and with segmentation. The Fire Dynamics Simulator (FDS) was applied to conduct CFD simulation, which is a large-eddy simulation (LES) program and developed by the National Institute of Standards and Technology (NIST) (McGrattan, McDermott, Weinschenk, and Overholt, 2013; Qi, Wang, and Zmeureanu, 2014). It has been widely employed to study fire smoke transport in buildings. The grid size varies from $0.25 \mathrm{~m} \times 0.25 \mathrm{~m} \times$ $0.25 \mathrm{~m}$ to $0.5 \mathrm{~m} \times 0.5 \mathrm{~m} \times 0.5 \mathrm{~m}$. The total grids number is around 150,000 . The heat release rate (HRR) is assumed to be $5 \mathrm{MW}$, which is a typical design fire (Klote, Milke, Turnbull, Kashef, and Ferreira, 2012). The required ventilation flow rate for removing smoke is decided by HRR and space height (Klote et al., 2012), which is $274 \mathrm{~m}^{3} / \mathrm{s}$ for the scenario no segmentation and $110 \mathrm{~m}^{3} / \mathrm{s}$ for the scenario without segmentation (Table 1).

Table 1: FDS simulation cases design.

\begin{tabular}{|c|c|c|}
\hline Cases & $\begin{array}{c}\text { Heat release } \\
\text { rate, MW }\end{array}$ & $\begin{array}{c}\text { Ventilation flow } \\
\text { rate, } \mathrm{m}^{3} / \mathrm{s}\end{array}$ \\
\hline No segmentation & 5 & 274 \\
\hline With segmentation & 5 & 110 \\
\hline
\end{tabular}

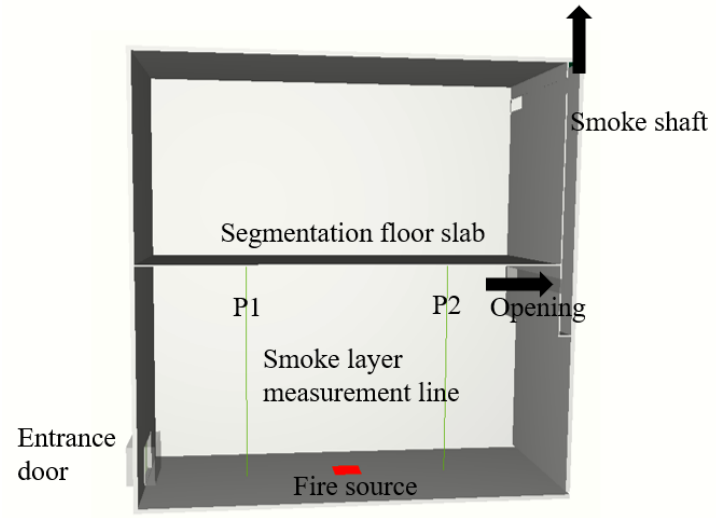

Figure 2: The scheme of atrium.

\section{Energy simulation}

To study the benefits of NV, two motorized vents are designed on the top and bottom of north glazing façade with height of $5.8 \mathrm{~m}$ and $28.8 \mathrm{~m}$ (Figure 1, top and bottom openings). For the case with segmentation floor slab, there is a motorized grille mounted on the floor slab as a connection allowing the buoyancy-driven flow for NV. Once a fire happened, the motorized grille will be closed. The detailed composition of the atrium's construction and their thermal properties defined as same as the ASHRAE climate zone 7-8 (ASHRAE, 2007), and the key dimensional parameters of the atrium is shown in the Table 2. Furthermore, the solar transmittance and conductivity of the glazing façade are 0.36 and 0.0626 $\mathrm{W} /(\mathrm{m} \cdot \mathrm{K})$ with $2.4 \mathrm{~cm}$ thickness.

Table 2: Atrium information.

\begin{tabular}{|c|c|c|}
\hline \multicolumn{2}{|c|}{ Floor area, $\mathrm{m}^{2}$} & 355.36 \\
\hline \multirow{2}{*}{$\begin{array}{c}\text { Facade area, } \\
\mathrm{m}^{2}\end{array}$} & North & 235.44 \\
\hline & West & 515.71 \\
\hline \multirow{2}{*}{$\begin{array}{l}\text { Window vents } \\
\text { area, } \mathrm{m}^{2}\end{array}$} & Top & \multirow{2}{*}{16.90} \\
\hline & Bottom & \\
\hline \multirow{2}{*}{$\begin{array}{l}\text { Facade area } \\
\text { ratio }\end{array}$} & North & 0.65 \\
\hline & West & 0.90 \\
\hline \multicolumn{2}{|c|}{ Interior ceiling, $\mathrm{m}^{2}$} & 233 \\
\hline \multicolumn{2}{|c|}{ Exterior ceiling, $\mathrm{m}^{2}$} & 122 \\
\hline \multirow{3}{*}{$\begin{array}{l}\text { Interior wall, } \\
\mathrm{m}^{2}\end{array}$} & South & 285 \\
\hline & East & 916 \\
\hline & West & 344 \\
\hline \multirow{3}{*}{$\begin{array}{l}\text { Exterior wall, } \\
\mathrm{m}^{2}\end{array}$} & North & 363 \\
\hline & West & 572 \\
\hline & South & 77.8 \\
\hline \multicolumn{2}{|c|}{ Interior floor, $\mathrm{m}^{2}$} & 342 \\
\hline \multicolumn{2}{|c|}{ Horizontal opening, $\mathrm{m}^{2}$} & 13.2 \\
\hline
\end{tabular}

To study the performance of NV for ventilative cooling in the atrium, Energyplus is used which includes the airflow network and can simulate the coupled heat and air transfer in buildings $(\mathrm{Gu}$, n.d.; Lawrence Berkeley National Laboratory, 2009). Four cases were designed here: (a) Case A-M: only mechanical cooling (MC) when cooling is required; (b) Case A-NV: mixed ventilation using NV and MV, when the outdoor condition is proper; (c) Case SA-M: atrium with segmentation and operation using MC; (d) Case SA-NV: atrium with segmentation and operation using $\mathrm{MC}$ and $\mathrm{NV}$. The weather data was 
Energyplus weather file (EPW) from the Canadian Weather for Energy Calculations (CWEC) for Montreal (Energyplus: Weather data, 2018). Table 3 lists the simulation cases and the weather condition for NV. The occupied schedule is between 8:00 and 22:00 (15 hours every day). The internal heat gain includes lights, equipment, and people activity, which are set as $10 \mathrm{~W} / \mathrm{m}^{2}$, $7 \mathrm{~W} / \mathrm{m}^{2}$ and $132 \mathrm{~W} /$ person respectively. The number of people takes 0.02 person $/ \mathrm{m}^{2}$. Except the external façade and ground, the remaining boundaries are set to be adiabatic. However, the thermal mass of the internal walls will be simulated in the airflow network heat transfer.

Table 3: Energy simulation cases design.

\begin{tabular}{|c|c|c|}
\hline Cases & Cooling mode & $\begin{array}{c}\text { Weather condition for } \\
\text { NV }\end{array}$ \\
\hline A-M & $\mathrm{MC}$ & 1 \\
\hline A-NV & $\mathrm{MC}+\mathrm{NV}$ & $\begin{array}{c}\mathrm{T}_{\mathrm{a}}<\mathrm{T}_{\text {in }} \text { and } 15 \leq \mathrm{T}_{\mathrm{a}} \leq \\
24{ }^{\circ} \mathrm{C}, \\
\mathrm{T}_{\mathrm{d}} \leq 13.5^{\circ} \mathrm{C}, \\
\mathrm{v}_{\mathrm{w}} \leq 7.5 \mathrm{~m} / \mathrm{s}\end{array}$ \\
\hline SA-M & MC & 1 \\
\hline SA-NV & $\mathrm{MC}+\mathrm{NV}$ & $\begin{array}{c}\mathrm{T}_{\mathrm{a}}<\mathrm{T}_{\text {in }} \text { and } 15 \leq \mathrm{T}_{\mathrm{a}} \leq \\
24^{\circ} \mathrm{C}, \\
\mathrm{T}_{\mathrm{d}} \leq 13.5^{\circ} \mathrm{C}, \\
\mathrm{V}_{\mathrm{w}} \leq 7.5 \mathrm{~m} / \mathrm{s}\end{array}$ \\
\hline
\end{tabular}

$\mathrm{T}_{\mathrm{a}}$ : ambient temperature; $\mathrm{T}_{\mathrm{d}}$ : dew temperature; $\mathrm{v}_{\mathrm{w}}$ : wind speed

\section{Results and discussion}

\section{Fire smoke simulation}

Figure 3 presents the smoke layer height and relative layer height at location $\mathrm{P} 1$, which is near the entrance door (see Figure 2). It can be seen that the smoke layer height is almost the same, around $3 \mathrm{~m}$ high. However, for cases with segmentation, the space height is less than the height of the case without segmentation, the relative smoke layer height is much higher than the case without segmentation. Therefore, there is more smoke-freer zone between the entrance door and the fire source when the segmentation is added. Actually, due to the block of the segmentation floor slab, whole upper space of the atrium is free of smoke. However, for the case without segmentation, the upper space of the atrium is full of smoke because the smoke height for no segmentation case is only $3 \mathrm{~m}$.

Figure 4 presents the smoke layer height and relative layer height at location P2 (see Figure 2). It can be seen that the smoke layer height of no segmentation is higher than that of with segmentation (Figure 4.(a)). However, the relative smoke layer height is almost the same as the case with no segmentation.

In conclusion, with the aspect of fire smoke protection, the case with segmentation has better performance, which is free of smoke in the space above the segmentation floor slab and has higher relative smoke layer height at the place between the entrance door and the fire source.

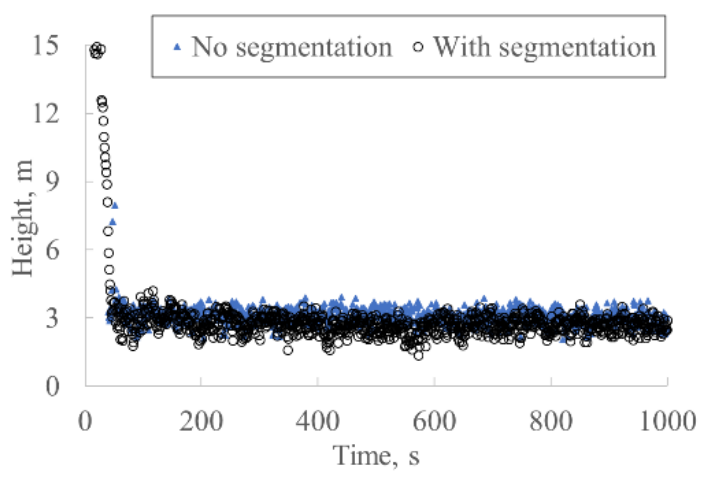

(a)

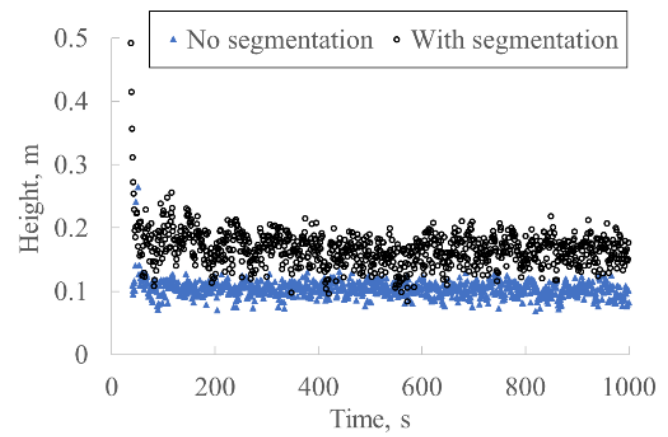

(b)

Figure 3: Position P1. (a) smoke layer height; (b) relative smoke layer height.

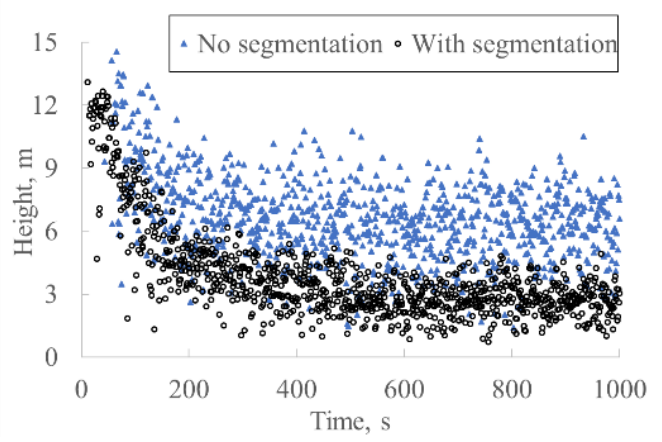

(a)

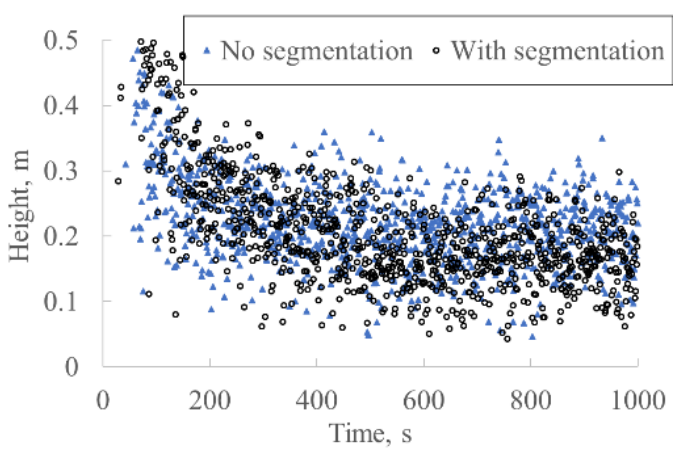

(b)

Figure 4: Position P2. (a) smoke layer height; (b) relative smoke layer height.

\section{Energy simulation}

This section first demonstrates cooling load in the four cases from June to September. Then, to evaluate the performance of $\mathrm{NV}$, a specific week was chosen to 
analyze, which includes the best and worst performance of NV for cooling. Finally, two days in the specific week were selected to discuss the cooling load of the atrium.

\section{Monthly cooling load}

The monthly cooling load between June and September is shown in Figure 5. By comparing A-M and A-NV, it can be found that $\mathrm{NV}$ can significantly reduce cooling load, about $28 \%$ of total cooling load is saved during the four months. After dividing the atrium into two parts with segmentation, the total cooling load is found to increase around $13 \%$ by comparing cases A-M and SA-M (see Figure 5), because more solar energy is absorbed by the segmentation floor slab.

For the cases of the atrium with segmentation, NV reduces less cooling load compared with the cases of the atrium without segmentation. The cooling load savings of the NV can only achieve around $15 \%$, much less than the scenario without the segmentation, which is $28 \%$. This is because the cooling load of cases with segmentation is higher and the segmentation increases friction for NV, leading to less airflow rate.

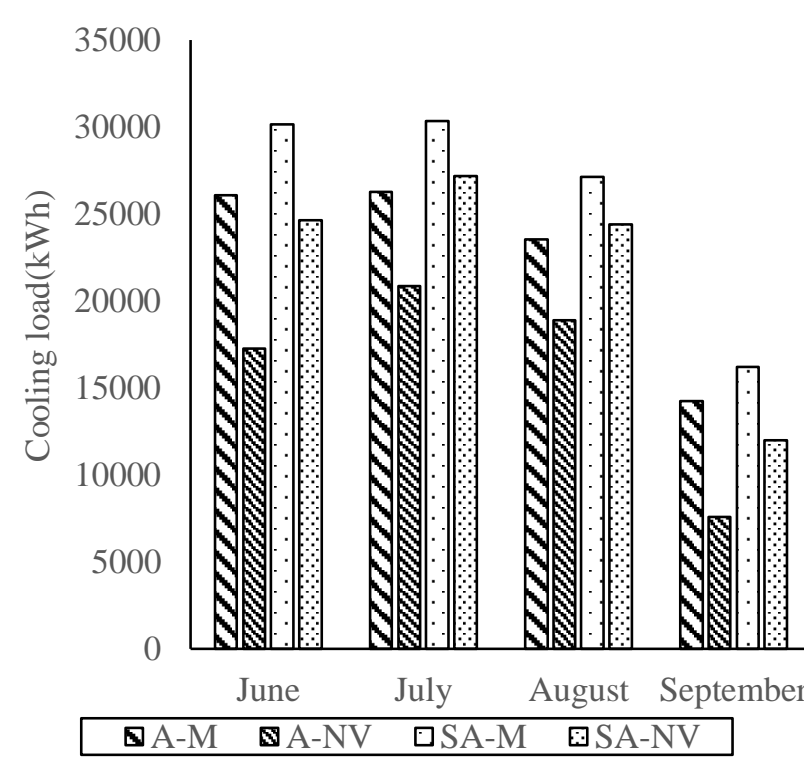

Figure 5: Monthly cooling load.

\section{Cooling load during a specific week}

Figure 6 presents the cooling load of the cases with and without NV during a specific week (08/22-08/27). The accumulated cooling load savings for the case without segmentation by NV in this week are around $56 \%$ (about $2192 \mathrm{kWh}$ ), comparing cases A-M and A-NV. Figure 6 also indicates that the daily cooling load savings are mainly determined by the outdoor temperature. Generally, the lower of the outdoor temperature contribute to more cooling load saving. The cooling load are almost the same on Aug. 22 and Aug. 23 for both cases with and without NV mode, because the outdoor temperature is higher than $24^{\circ} \mathrm{C}$ and the venting openings are closed according to the operation criteria in Table 3. When outdoor temperature is lower than $20^{\circ} \mathrm{C}$, i.e. during the days of $24^{\text {th }}, 25^{\text {th }}$ and $27^{\text {th }}, \mathrm{NV}$ can almost cover all the cooling load and does not need MC for cases without segmentation (see Figure 6.(a)). Therefore, the peak cooling load is reduced significantly. For the cases with segmentation shown in Figure 6.(b), NV can only cover cooling load partially due to the higher cooling load and less capability of heat removing of NV (flow rate is less when segmentation is added), only $29.7 \%$ cooling load is saved (around $1342 \mathrm{kWh}$ ).

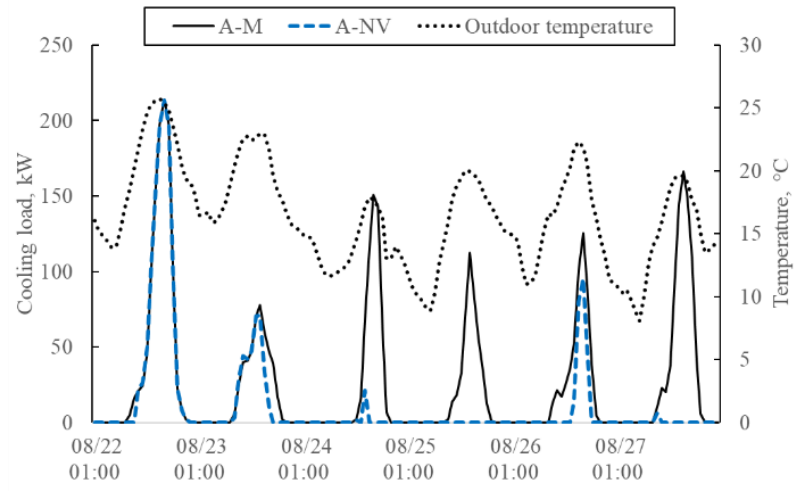

(a)

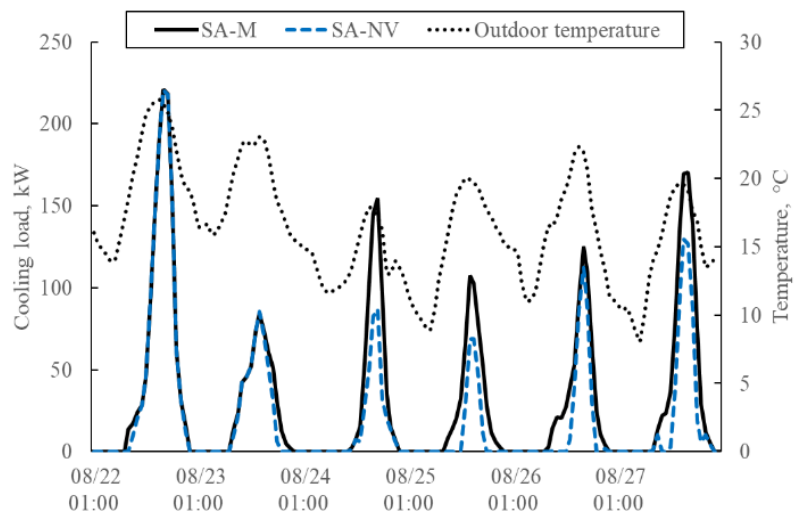

(b)

Figure 6: Cooling load in a specific week. (a) atrium without segmentation; $(b)$ atrium with segmentation.

\section{Cooling load during two specific days}

To look into the daily cooling load, two days were selected: the worst day, 08/22, and the best day, 08/25. The day, 08/22, has only limited time with NV during the morning (Figure 7). The cooling load profiles for the cases with and without NV, as shown in Figure 7 are almost the same.

The day of $08 / 25$ presents the best day for ventilative cooling, when $\mathrm{NV}$ works during the occupant time (see Figure 8). The reduced cooling load is $108 \mathrm{kWh}$ for case A-NV and $68 \mathrm{kWh}$ for case SA-NV. The atrium without segmentation does not need the MC (Figure 8.(a)), but the atrium with segmentation still needs MC (Figure 8.(b)), because the added segmentation resulting in more friction and less NV flow in case SA-NV.

Through the energy simulation and fire smoke simulation, it can be found that with a smoke shaft, adding segmentation floor slab can improve the fire protection performance but will decrease the capability of ventilative cooling due to the increased friction caused by 
segmentation floor slab. Therefore, it is quite necessary to evaluate both of fire protection performance and energy efficiency for high-rise ventilation design.

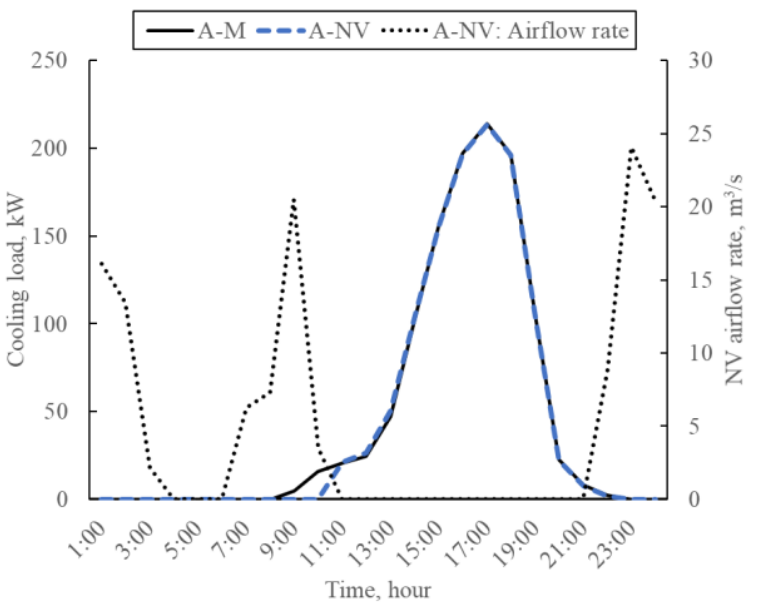

(a)

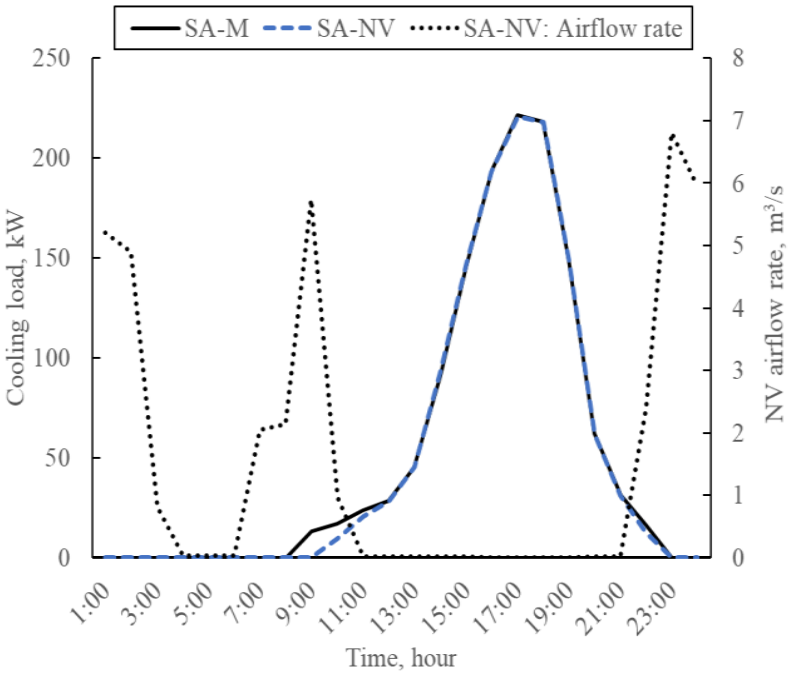

(b)

Figure 7: Cooling load on day 08/22. (a) atrium without segmentation; (b) atrium with segmentation.

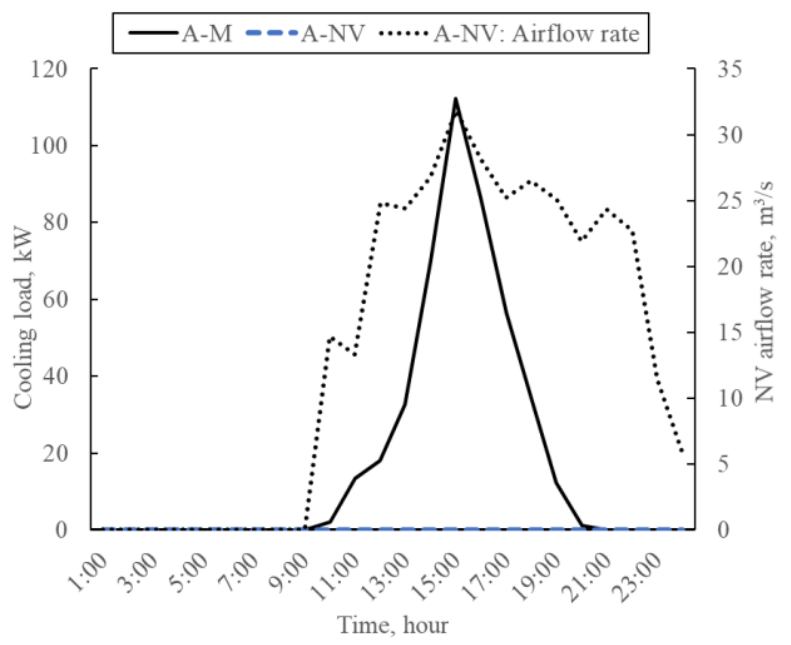

(a)

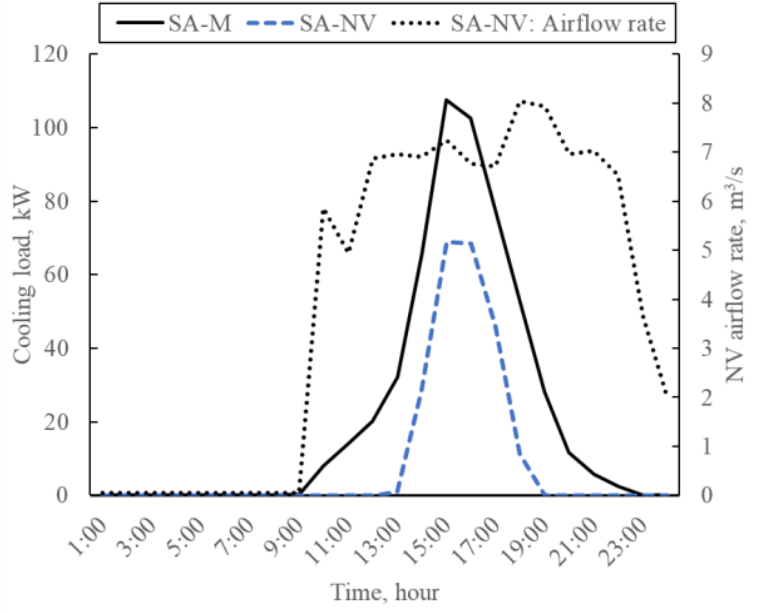

(b)

Figure 8: Cooling load on day 08/25. (a) atrium without segmentation; (b) atrium with segmentation.

\section{Conclusion}

This paper investigated the impacts of fire safety design on the high-rise ventilative cooling performance. A typical fire protection measure was studied in the atrium of an institutional high-rise building in Montreal: adding segmentation floor slab and a smoke shaft. Fire smoke model and building energy model were developed and simulations were conducted. The study reached the following major conclusions:

(1) The fire smoke simulations show that the segmentation could effectively protect the upper space which is far from the fire source. It will also contribute to higher relative smoke layer height at the place between the entrance door and the fire source.

(2) The energy simulations show that NV can significantly reduce cooling load. For the case studied, about $28 \%$ of the total cooling load is reduced during the four months (from June to September) when the atrium is without segmentation floor slab. When the segmentation is added, only $13 \%$ of the cooling load is reduced by NV, because of the increased flow friction and total cooling load. The cooling energy savings is closely related to the outdoor temperature. In this study case, when outdoor temperature is lower than $20^{\circ} \mathrm{C}, \mathrm{NV}$ could cover all the cooling load when the atrium is without the segmentation floor slab.

(3) The energy and fire smoke simulations found that with a smoke shaft, adding segmentation floor slab can improve the fire protection performance but leads to reduced capability of ventilative cooling. Therefore, it is quite necessary to evaluate both of fire protection performance and energy efficiency for high-rise ventilation design.

\section{Reference}

Aflaki, A., Mahyuddin, N., Al-Cheikh Mahmoud, Z., \& Baharum, M. R. (2015). A review on natural ventilation applications through building façade components and ventilation openings in tropical climates. Energy and Buildings, 101, 153-162. 
Artmann, N., Manz, H., \& Heiselberg, P. (2007). Climatic potential for passive cooling of buildings by nighttime ventilation in Europe. Applied Energy, 84(2), 187-201.

ASHRAE. (2007). NSI/ASHRAE/IES standard 90.1-2007 energy standard for buildings except low-rise residential buildings.

Cheng, J., Qi, D., Katal, A., Wang, L. L., \& Stathopoulos, T. (2018). Evaluating wind-driven natural ventilation potential for early building design. Journal of Wind Engineering and Industrial Aerodynamics, 182(April), 160-169.

Cheng, J., Qi, D., Wang, L., \& Athienitis, A. (n.d.). Whole-Building Simulation of Hybrid Ventilation based on Full-scale Measurements in an Institutional High-rise Building for Predictive Control. In Proceedings from IBPSA2017. San Francisco.

Energyplus: Weather data. (2018). Retrieved October 25, 2018, from https://energyplus.net/weather

$\mathrm{Gu}$, L. (n.d.). Airflow network modeling in EnergyPlus. In Proceedings from IBPSA2007 (pp. 964-971). Beijing.

Hu, J., \& Karava, P. (2014). Model predictive control strategies for buildings with mixed-mode cooling. Building and Environment, 71, 233-244.

Klote, J. H., Milke, J. A., Turnbull, P. G., Kashef, A., \& Ferreira, M. J. (2012). Handbook of Smoke Control Engineering. Atlanta, GA.: American Society of Heating Refrigerating and Air-Conditioning
Engineers.

Lawrence Berkeley National Laboratory. (2009). Input Output Reference. EnergyPlus.

Malkawi, A., Yan, B., Chen, Y., \& Tong, Z. (2016). Predicting thermal and energy performance of mixed-mode ventilation using an integrated simulation approach. Building Simulation, 9, 335346.

McGrattan, K., McDermott, R., Weinschenk, C., \& Overholt, K. (2013). Fire Dynamics Simulator User's Guide. Gaithersburg, MD.

Moosavi, L., Mahyuddin, N., Ab Ghafar, N., \& Azzam Ismail, M. (2014). Thermal performance of atria: An overview of natural ventilation effective designs. Renewable and Sustainable Energy Reviews, 34, 654-670.

Qi, D., Wang, L., \& Zmeureanu, R. (2014). An analytical model of heat and mass transfer through nonadiabatic high-rise shafts during fires. International Journal of Heat and Mass Transfer, 72, 585-594.

Venticool. (2016). IEA EBC Annex 62: The IEA project on ventilative cooling.

Wikipedia. (2018). Skyscraper fire. Retrieved October 25, 2018 , from https://en.wikipedia.org/wiki/Skyscraper_fire.

Yuan, S., Vallianos, C., Athienitis, A., \& Rao, J. (2018). A study of hybrid ventilation in an institutional building for predictive control. Building and Environment, 128, 1-11. 